JIN XIN CAO, Ph.D. ${ }^{1}$

(Corresponding author)

E-mail: imucjx@163.com

XIAO HAN LIU, Student ${ }^{1,2}$

E-mail: liuxiaohan1201@163.com

${ }^{1}$ Inner Mongolia University, Institute of Transportation

No. 24 Zhaojun Road, Yuquan District, Hohhot,

010070, China

2 Southwest Jiaotong University,

School of Transportation and Logistics

Xipu Town, Pi County, Chengdu, 611756, China
Traffic Engineering

Preliminary Communication

Submitted: July 20, 2015

Accepted: Apr. 27, 2016

\title{
RESEARCH ON THE EQUILIBRIUM SPEED-DENSITY RELATIONSHIP AROUND FLYOVER WORK ZONE
}

\begin{abstract}
Increasing traffic demand has already reached the capacity of existing traffic facilities in most cities. In order to alleviate the traffic pressure and expand the capacity of the road network, constructing flyovers has become an effective way in most cities in China. During the period of the flyover construction, work zones occupy road space, impact traffic flow characteristics and driver behaviour; therefore, this causes a significant reduction of the capacity. Researching of the traffic flow characteristics during the period of flyover construction can improve traffic organization and traffic safety around work zones. This study analyses the traffic flow characteristics around the flyover work zone based on the site data collected in Hohhot City, China. This study shows that the traditional Logistic model for the equilibrium speed-density relationship is not applied to the traffic flow around the flyover work zone. Based on an in-depth analysis of the traffic flow characteristics and specific driver behaviours, this paper proposes an improved Logistic model to depict the equilibrium speed-density relationship around the flyover work zone. To analyse the mathematical characteristics of the speed-density relationship, this paper proposes a method to insert virtual data points into the initial data, which can make the fit curve be continuous.
\end{abstract}

\section{KEY WORDS}

flyover; traffic flow characteristic; logistic model; work zone;

\section{INTRODUCTION}

Research on the traffic flow characteristics around work zones, especially freeway work zones, has been conducted for years. Enberg and Mannan studied traffic flow characteristics of expressways at work zones and found the speed limit of vehicle travel speed affected markedly the time headway [1]. Sisiopiku and Lyles studied vehicle speed distribution and influence factors at work zones, and the result shows that vehicle travel speed is usually higher than the speed limit at work zones and the vehicle travel speed is related to the number of open lanes [2]. Jiang studied the capacity, the queue evacuation rate, and the vehicle travel speed at freeway work zones under congested condition and free-flow condition, respectively [3]. The results can be used to predict traffic congestion, to evaluate traffic delays, and analyse the travel cost. Zhou and Wu studied various factors influencing the capacity at freeway work zones with VISSIM simulation software [4]. They found lots of complex factors influencing capacity of highway work zones, including heavy vehicle rate, length of work zones, longitudinal gradient and types of closed lanes. Radhakrishnan et al. analysed traffic flow characteristics of various typical work zones and studied the relationship between volume and speed under dynamic and non-dynamic merged flow [5]. They analysed the traffic flow characteristics of a typical crossover-type work zone in Missouri. Traffic characteristics under the two conditions were studied based on the speed-flow relationship, capacity, and time headway parameters. An increase in traffic flow on one of the afternoons resulted in a continuous decrease in the speed of vehicles, leading to congested conditions at certain locations within the work zone. The study indicated the general behaviour of Missouri drivers and helped establish the parameters that could be used to model and simulate the traffic flow at other work zones and freeways in Missouri. Chen et al. established a traffic system simulation model for urban expressways, which is capable of simulating and analysing traffic flow condition and facility capacity at work zones by the computer simulation [6]. Meng and Weng presented a CA model for complex roadway work zones. It improves speed and site update rules while vehicles are passing through work zones [7]. Weng and Meng studied the effects of environment, vehicles and driver characteristics on the risky driving behaviour at work zones, a decision tree is developed by using the classification and 
regression tree (CART) algorithm to graphically display the relationship between the risky driving behaviour and its influencing factors [8]. Hong et al. proposed an improved collision frequency model based on the length measurement error at work zones. It is proven to be better than traditional collision frequency models in the aspect of data goodness of fit [9]. Weng et al. evaluated rear-end crash risk associated with work zone operations for four different vehicle-following patterns: car-car, car-truck, truck-car and truck-truck [10]. The deceleration rate to avoid the crash (DRAC) is adopted to measure the work zone rear-end crash risk. Results show that the car-truck following pattern has the largest rear-end crash risk, followed by truck-truck, truck-car and car-car patterns. Xie presented a series of principles for traffic organization during the flyover construction, such as regional traffic organization, work zone traffic organization, temporary traffic safety facilities, and emergency plan design [11]. Weng et al. investigated the drivers' merging behaviour and the rear-end crash risk in work zone merging areas during the entire merging implementation period from the time of starting a merging manoeuvre to that of completing the manoeuvre [12]. Results show that the merging vehicle has a bigger probability of completing a merging manoeuvre quickly under one of the following situations: (i) the merging vehicle moves relatively fast; (ii) the merging lead vehicle is a heavy vehicle; and (iii) there is a sizable gap in the adjacent through lane. However, at present, most studies aim at general work zones, and there are few studies for flyover work zones. Therefore, an in-depth study of the traffic flow characteristics at flyover work zones is significant for traffic organization, optimization, and control.

With the rapid development of urbanization and motorization in China, traffic problems have become ever more significant. Constructing flyovers and upgrading arterials to expressways, have become a major way to alleviate traffic congestion. However, during the flyover construction period, the probability of road traffic accidents increases, road traffic capacity decreases, and certain impact on the surrounding road environment is produced. In recent years, the pace of urban construction has been fast. In particular, some large construction projects occupy the road space for a long time so that they produce a lot of traffic problems and seriously affect the residents' normal lives. Therefore, it is very important to analyse the impacts of flyover work zones on normal traffic, so as to improve the traffic organization and management.

\section{TRAFFIC FLOW CHARACTERISTICS AT FLYOVER WORK ZONES}

The flyover construction refers to fully enclosed road engineering operations which occupy the existing roads. In general, a flyover construction is divided into six stages:

Stage 1: construct pile foundations, pile caps, and pier columns of middle piers;

Stage 2: widen road base, move pipelines, construct temporary pavements;

Stage 3: construct cast-in-place box girder;

Stage 4: construct the pavement of the driveway;

Stage 5: construct non-motor ways and pavements;

Stage 6: construct traffic safety facilities, landscaping, lighting, and other appurtenant works.

Impact on traffic flow during Stage 2 and 3 is most obvious and complex, so this paper mainly focuses on these two stages.

The operation at the work zone is entirely enclosed. In most cases, there is a temporary traffic channel between two work zones in order to satisfy the traffic demand, but traffic markings and traffic channelized devices are not fully set up in the channel. These roadway characteristics can cause very complicated traffic flow characteristics around work zones.

Around work zones, drivers need to timely change the driving behaviour to adapt to the change of the roadway condition. Due to the randomness, mutability, complexity of work zones, drivers are required to perform high degrees of specificity and sensitivity. Drivers have to seek the right time to merge into the main road and give way to each other to avoid possible collisions while passing through work zones. Under this circumstance, vehicles are highly affected by the surrounding vehicles, and the drivers are forced to perform car-following and lane-changing behaviours, which can be identified as a non-free state.

\section{DATA COLLECTION AND ANALYSIS}

\subsection{Data collection}

In this paper, the site data are collected near the intersection of the South $2^{\text {nd }}$ Ring Road and Zhaojun Road, in Hohhot City, China. Before the construction of the flyover, South $2^{\text {nd }}$ Ring Road was an eight-lane arterial road of the city with a speed limit of $60 \mathrm{~km} / \mathrm{h}$. It is in Stage 2 of flyover construction while the data are being collected. The observing time is from 7:00 a.m. to 11:00 a.m. on the $8^{\text {th }}$ November, 2014.

As can be seen in Figure 1, the survey used a video camera to collect traffic volume of Sections B and C. This method can collect the real volume of a certain time interval. The method requires Camera 1 to be located beside the road and focused on the conflict area in order to capture vehicles passing Sections B and C at the same time. The volume of Section $A$ is equal to the sum of the volume of Sections $B$ and $C$, because of the short distance among the three sections. The collection time interval of traffic volume is $15 \mathrm{~min}$ for 
a long time observation from 7:00 a.m. to 11:00 a.m. and $10 \mathrm{~s}$ for a short time observation.

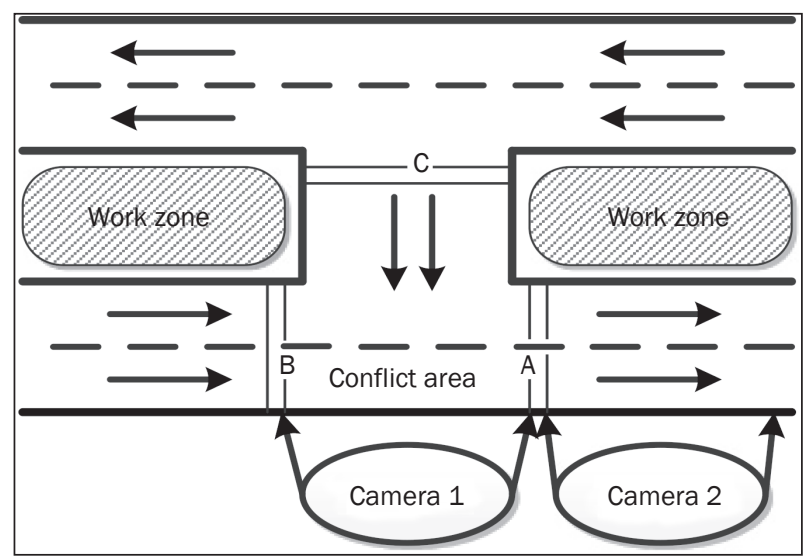

Figure 1 - Traffic flow data collection method

Spot speed is the speed when a car passes through a site, also known as the instantaneous speed. It is one of important parameters to describe traffic conditions at a site. It needs Camera 2 to be located beside Section A, so that the video camera is able to clearly and fully capture vehicles driving from Section A to the downstream section. Therefore, speed can be calculated by a specific travel time for a certain distance, i.e. $20 \mathrm{~m}$.

Traffic flow density refers to the number of vehicles for the unit length of a lane at an instantaneous time. It needs Camera 2 to be located beside a certain site on the downstream. The observation length interval is $50 \mathrm{~m}$. A short piece of video can be divided into a number of frames. By counting the number of vehicles in each frame, and by calculating the average number of vehicles of all frames, the average number of vehicles is used to obtain the number of vehicles for $1 \mathrm{~km}$. The illustrative screenshots of the video are shown in Figure 2.

\subsection{Data analysis}

Figure 3 shows the traffic flow rate from 7 a.m. to 11 a.m. at Sections A, B, and C. According to Figure 3, the change of the traffic flow rate of Section $A$ is small, the standard deviation is 253.98 and the coefficient of variation is $11.82 \%$. The average traffic flow rate is

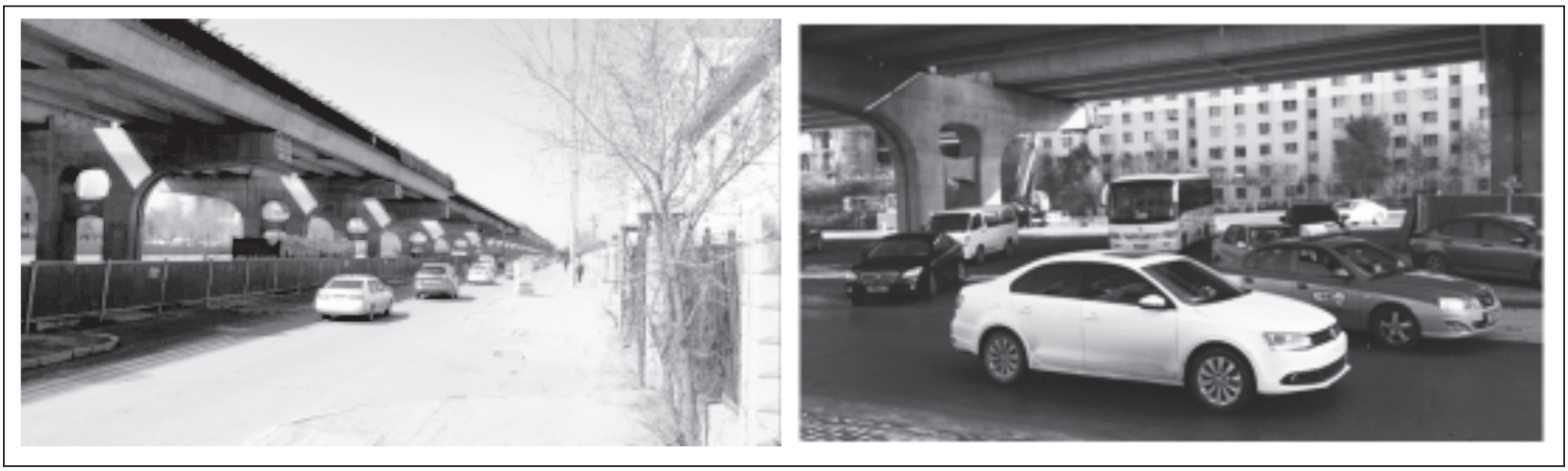

Figure 2 - Illustrative screenshots of the video

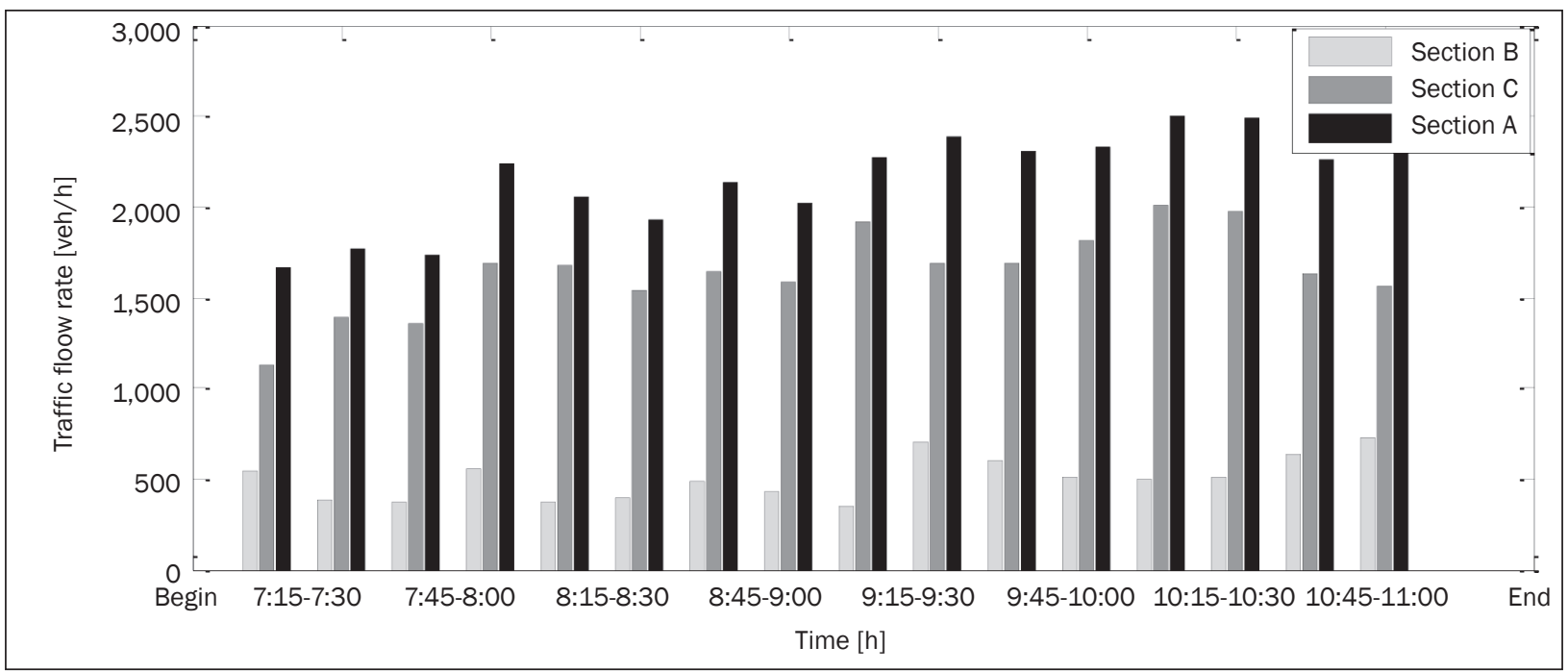

Figure 3 - Traffic rate flow of Section A, B, C 
2,295 veh/h, and the peak hour is from 9:30 a.m. to 10:30 a.m. Figure 3 intuitively reflects the traffic flow rate of Section B and Section C. According to Figure 3, the traffic flow rate of Section $\mathrm{C}$ accounts for $76.25 \%$ of the traffic flow rate of Section A. According to Figure 4, as an urban traffic arterial, Zhaojun Road carries a lot of traffic volume. However, during the flyover construction period, vehicles from Zhaojun Road can only turn right to travel through Section $\mathrm{C}$ so that they can pass through the intersection. Meanwhile, traffic volume from the other road is not really big on the basis of observed experience. So, there are some differences between the traffic flow rates of Section $\mathrm{C}$ and $\mathrm{B}$. The coefficient of variation of the traffic flow rate of Section $B$ and the traffic flow rate of Section $C$ are 15.72\% and $24.06 \%$, respectively. The heavy vehicle rate of Section B is $2.91 \%$, while Section C is $3.40 \%$. The calculation results reflect that the traffic flow rate of Section $B$ is more stable than that of Section C.

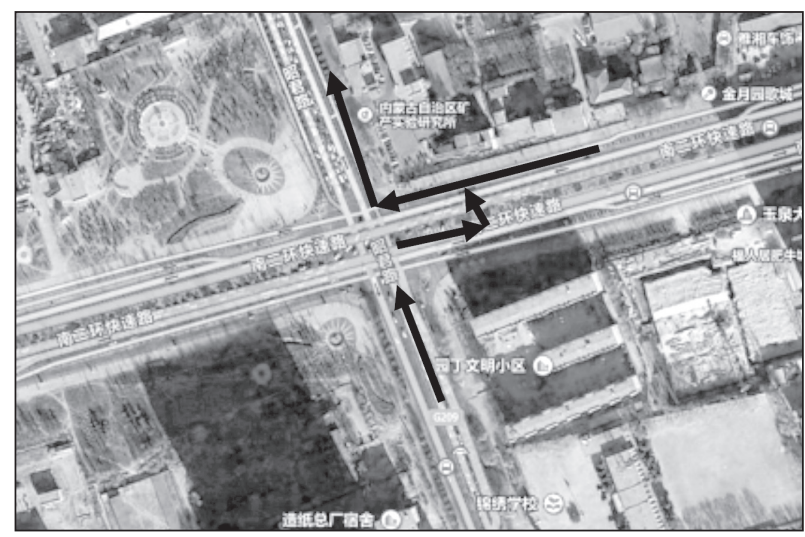

Figure 4 - Photo of road network in the area of intersection

Figure 5 shows the traffic volume of Section A for 200 seconds. According to Figure 5, the traffic volume of Section A fluctuates from 3 veh / 10 s to 10 veh / $10 \mathrm{~s}$, which reflects that the sub-hour traffic volume of Section A is unstable. For the whole observation time, the change of traffic flow rate of Section A is small. For every specific equally short time interval, the number of vehicles that passed Section A is variable, although the sum of vehicles that passed from $7: 15$ to $7: 30$ is not very different from other observation time.

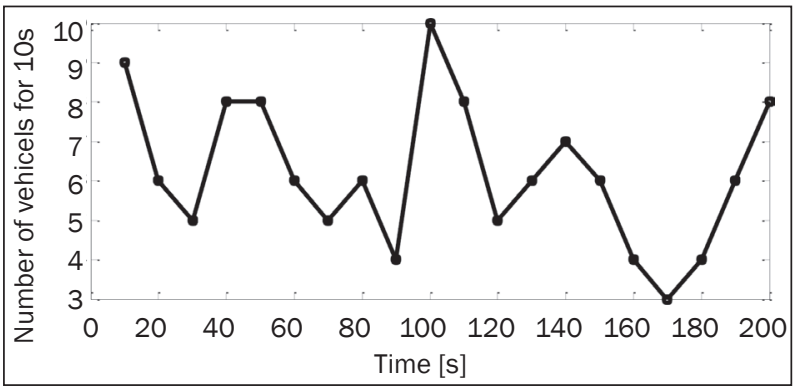

Figure 5 - Traffic volume of Section A for $200 \mathrm{~s}$
According to Table 1 and Figure 6, the time mean speed of samples is $19.54 \mathrm{~km} / \mathrm{h}$, which is much lower than the original time mean speed. The 85th percentile speed is $24.50 \mathrm{~km} / \mathrm{h}$, and the 15th percentile speed is $13.50 \mathrm{~km} / \mathrm{h}$. It shows that the work zone reduces the spot speed to a very low level.

Table 1 - Frequency distribution table for spot speed samples

\begin{tabular}{||c||c||c|c||c||}
\hline $\begin{array}{c}\text { Group } \\
(\mathrm{km} / \mathrm{h})\end{array}$ & $\begin{array}{c}\text { Middle } \\
\text { Speed }\end{array}$ & $\begin{array}{c}\text { Observe } \\
\text { Freq. in } \\
\text { Group }\end{array}$ & $\begin{array}{c}\text { \% Freq. } \\
\text { in Group }\end{array}$ & $\begin{array}{c}\text { Cum. \% } \\
\text { Freq }\end{array}$ \\
\hline \hline $11-13$ & 12 & 5 & 5 & 5 \\
\hline $13-15$ & 14 & 16 & 16 & 21 \\
\hline $15-17$ & 16 & 20 & 20 & 41 \\
\hline $17-19$ & 18 & 7 & 7 & 48 \\
\hline $19-21$ & 20 & 5 & 5 & 53 \\
\hline $21-23$ & 22 & 19 & 19 & 72 \\
\hline $23-25$ & 24 & 15 & 15 & 87 \\
\hline $25-27$ & 26 & 9 & 9 & 94 \\
\hline $27-29$ & 28 & 4 & 4 & 100 \\
\hline
\end{tabular}

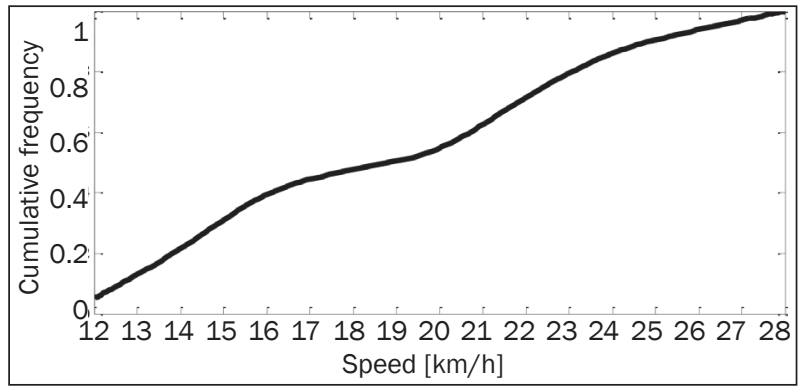

Figure 6 - Cumulative frequency distribution curve for spot speed samples

\section{SPEED-DENSITY MODEL FOR FLYOVER WORK ZONES}

\subsection{Logistic model for the equilibrium speed- density relationship}

Fundamental diagram describes the relationship between traffic flow and speed which is among the major models in the traffic engineering. The speed-density model is used to analyse the traffic flow stability, and determines the level of service of highways. As long as the relationship between speed and density can be established, the speed-volume and volume-density relationships can be determined, accordingly. Wang et al. proposed a Logistic model for the equilibrium speed-density relationship, which can fit the speed-density better than traditional models [13].

The model can be expressed by Equation 1, or equivalently by Equation 2: 


$$
\begin{aligned}
& v(k, \theta)=v_{b}+\frac{v_{f}-v_{b}}{\left[1+\exp \left[\frac{k-k_{t}}{\theta_{1}}\right]\right]^{\theta_{2}}} \\
& k=k_{t}+\theta_{1} \log \left[\exp \left[\frac{\log \left[\frac{v_{f}-v_{b}}{v_{-}}\right]}{\theta_{2}}\right]-1\right]
\end{aligned}
$$

This is the most general Logistic speed-density model in sigmoidal shape with five parameters. Notations $V_{f}$ and $V_{b}$ are the upper and lower asymptotes, respectively. Specifically, $V_{f}$ denotes the free flow speed, and $V_{b}$ denotes the average travel speed in the stopand-go condition. This parameter assumes that traffic has finite movements even in congested conditions. Notation $\theta_{1}$ is a scale parameter which describes how the curve is stretched over the whole density range, and $\theta_{2}$ is a parameter which controls the lopsidedness of the curve. Parameter $k_{t}$ is the turning point at which the speed-density curve makes the transition from the free-flow to the congested flow.

The model fits the observed density-speed relationship in most cases, so that it is widely applied to analyse traffic characteristics. Model parameters $\left(V_{f}, V_{b}, k_{f}\right)$ have actual physical significance, and outperform the
Greenshields model, Greenberg model, Underwood model, Northwestern model, and Del Castillo model from the aspect of the goodness-of-fit [13].

\subsection{The speed-density relationship model}

The key to analyse traffic flow characteristics is to build the relationship between speed and density. To obtain the relationship, there are two possible situations: one is that the fitting curve is continuous; the other is that the fitting curve is discontinuous. Figure 7 shows the flow chart of fitting the curve.

To fit the curve, the key step is to determine whether the curve is continuous. There is a method seeking the discontinuity density point of speed-density data points. The discontinuity density point can be called the key point, which is denoted by $T$. The method can be only used for monotonic curves which contain only one discontinuity point; where, $A$ is a set of density-speed points and set $A$ is assumed to have $n$ points. Point $i$ belongs to set $A$, where $x_{1} \leq x_{2} \leq x_{3} \leq \ldots \leq x_{n-2} \leq$ $x_{n-1} \leq x_{n}$, and let $b_{i}=\left|y_{i}-y_{i-1}\right|, i \geq 2$. So, if there is a key point, it should meet the following two conditions:

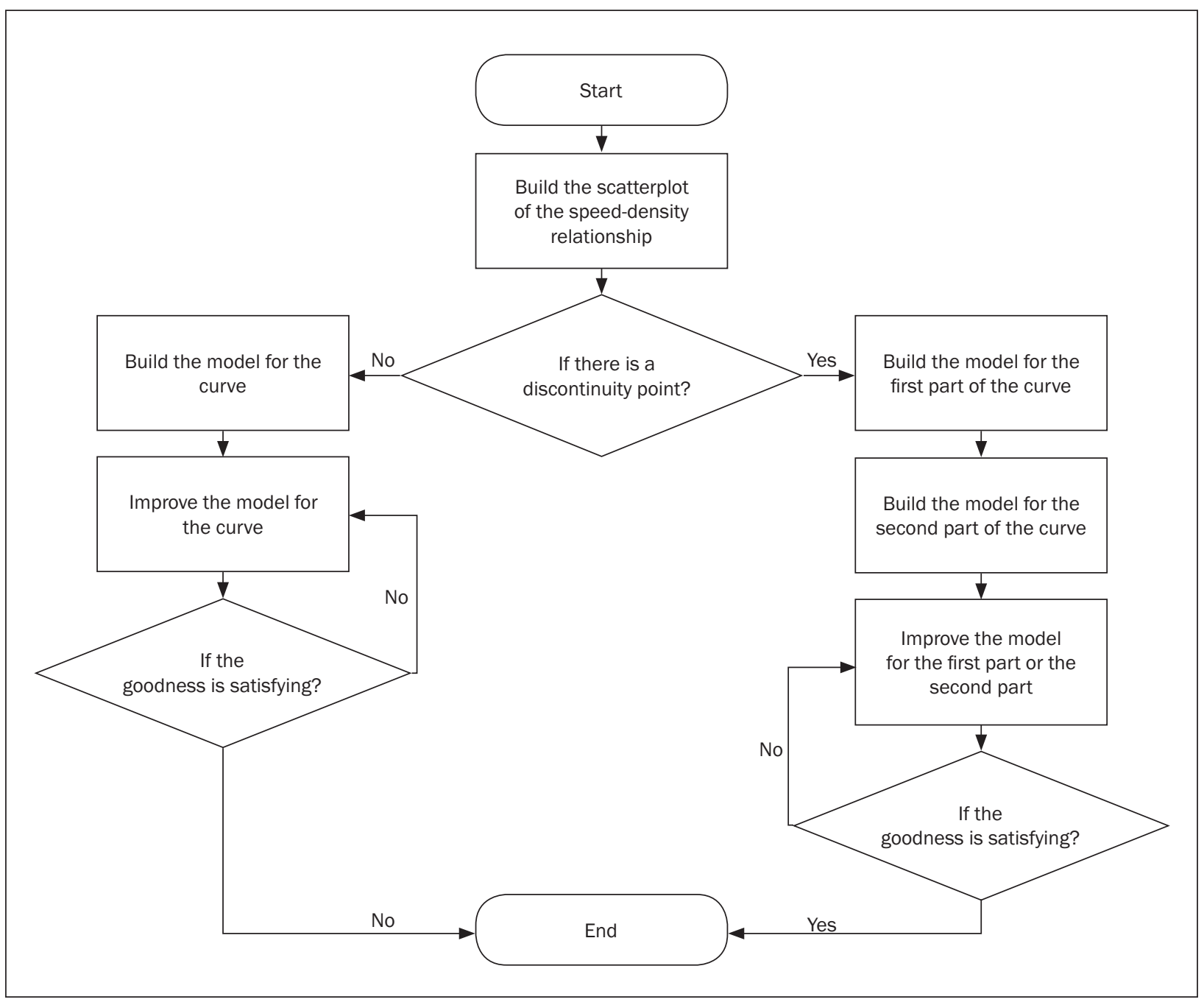

Figure 7 - The flow chart of fitting the curve 
Condition 1: For a $T, b_{T}$ must be a local maximum.

Condition 2: Every point in set $\left\{y_{1}, y_{2}, y_{3}, \ldots, y_{T-2}, y_{T-1}\right\}$ is larger than every point in set $\left\{y_{T+1}, y_{T+2}, y_{T+3}, \ldots, y_{T-1}, y_{T}\right\}$, when the curve is a decreasing function; every point in set $\left\{y_{1}, y_{2}, y_{3}, \ldots, y_{T-2}, y_{T-1}\right\}$ is smaller than every point in set $\left\{y_{T+1}, y_{T+2}, y_{T+3}, \ldots, y_{T-1}, y_{T}\right\}$, when the curve is an increasing function.

For Condition 1, the local maximum is the maximum value of $b_{i}$ for a selected group of $\left(x_{i}, y_{i}\right)$. The $b_{T}$ should be large enough in comparison to other $b_{i}$ 's in the group, so that it can be insured that the point can become a discontinuity point. It can be given a boundary value to judge whether $b_{T}$ meets the condition, and this usually depends on the specific question.

For Condition 2, this condition can guarantee that $T$ is really a discontinuity point rather than an upper boundary point or a lower boundary point in a group of stable points.

\subsection{Computational experiments}

Logistic model can accurately describe the speed-density relationship in most normal traffic environment, but it is not suitable for some special traffic environments, such as flyover work zones. The driving process is shown in Figure 8 . In the driving process, drivers first accept all sorts of relevant information by their senses, such as sight, hearing, touch and smell, namely, the sensation stage. Information produces consciousness by a series of comprehensive reactions in the brain. On the basis of consciousness, drivers can gain driving information, such as speed, time and distance, namely, the cognition stage. Drivers judge driving information to make a decision, namely, the judging stage. Finally, drivers operate vehicles according to the driving decision, namely, the execution stage. At flyover work zones, drivers usually change the driving behaviours in order to adapt to the specific traffic environment. Driving behaviours at flyover work zones can be quite different from general driving behaviour. Therefore, it is necessary to improve the Logistic model to fit the speed-density relationship at flyover work zones.

The speed-density relationship of the site under study in this paper is illustrated in Figure 9. Ganther form of splashes is divided into two parts: when the density is less than the key point; the splashes gather in a form; when density is larger than the key point; the splashes gather in another form. Therefore, if Logistic model is applied to fit the data, the results inevitably show large deviations with the actual data. Traffic flow density reflects the number of vehicles for a unit length of a lane and it is continuous. However, traffic flow speed reflects an average speed of vehicles and it is discontinuous. There are 92 speed-density points gained by artificial video technology. To be specific, Camera 2 shoots moving vehicles of Section A, and we

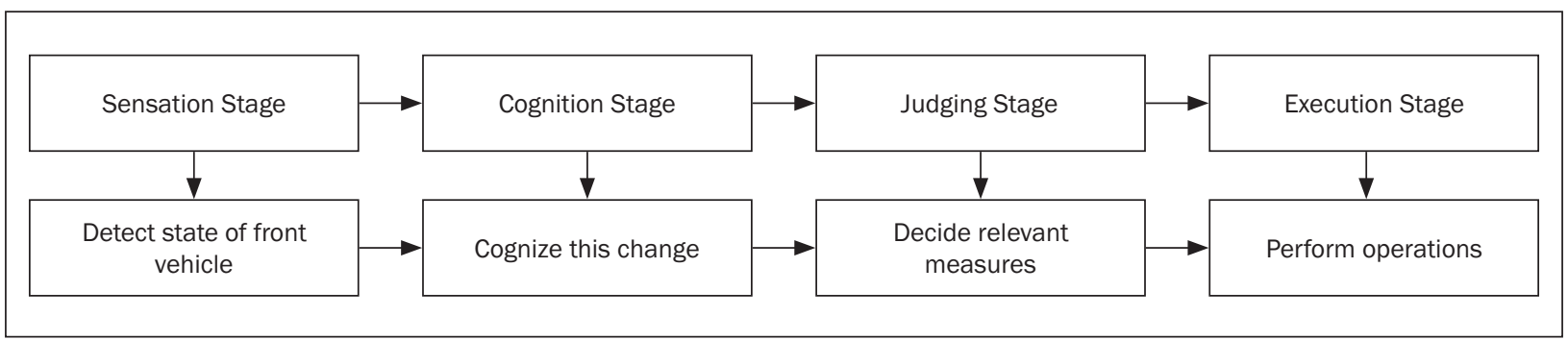

Figure 8 - The driving process

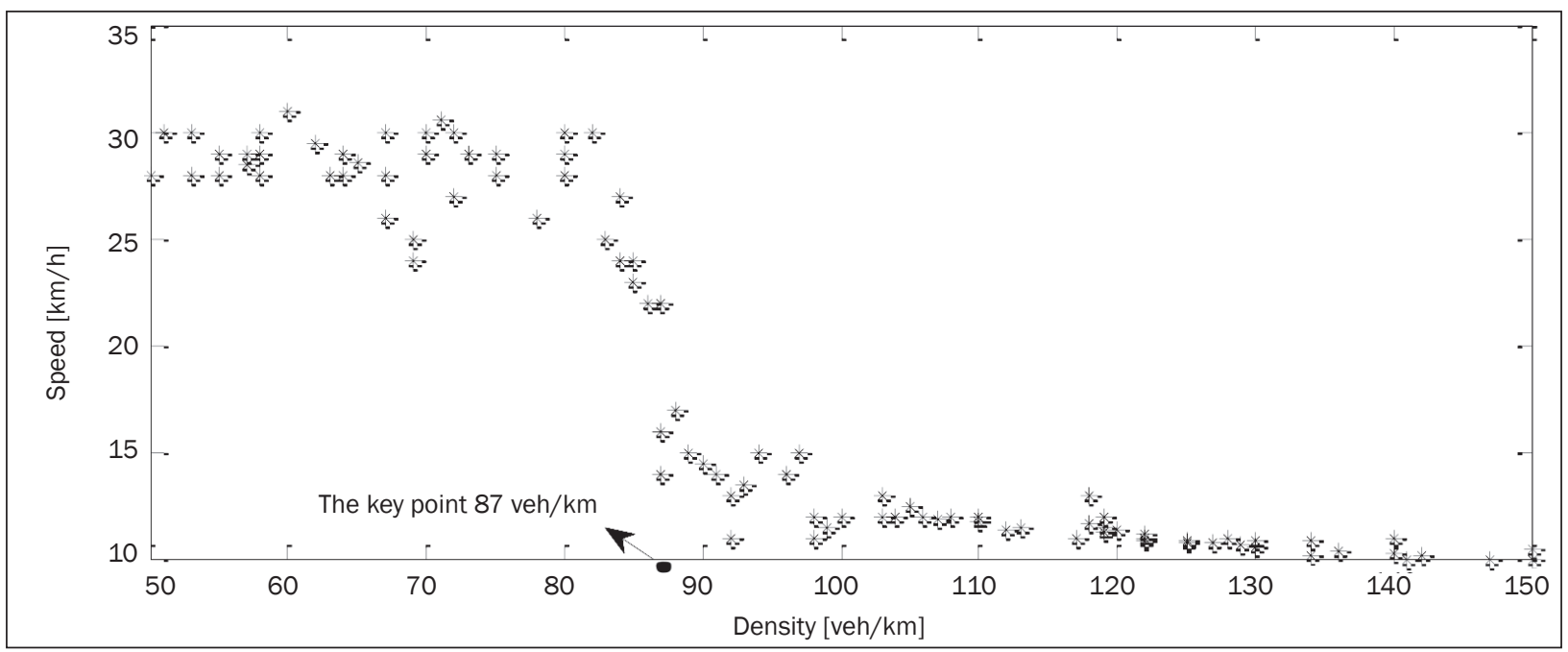

Figure 9 - The scatterplot of the speed-density relationship 
use the video to gain speed-density points by Equations 3 and 4:

$$
\begin{aligned}
& v=\frac{\sum_{i=1}^{n} v_{i}}{n} \\
& k=\frac{q}{v}=\frac{n / \Delta t}{\frac{1}{n} \sum_{i=1}^{n} v_{i}}=\frac{n^{2}}{\Delta t \sum_{i=1}^{n} v_{i}}
\end{aligned}
$$

\begin{tabular}{|c|c|c|c|c|c|c|c|c|c|c|}
\hline$k(v e h / k m)$ & 51 & 50 & 53 & 53 & 55 & 55 & 57 & 57 & 58 & 58 \\
\hline$v(\mathrm{~km} / \mathrm{h})$ & 30 & 28 & 30 & 28 & 29 & 28 & 29 & 28.5 & 30 & 29 \\
\hline $\begin{array}{l}\text { Absolute } \\
\text { difference }\end{array}$ & - & 2 & 2 & 2 & 1 & 1 & 1 & 0.5 & 1.5 & 1 \\
\hline$k(v e h / k m)$ & 58 & 60 & 62 & 63 & 64 & 64 & 65 & 67 & 67 & 67 \\
\hline$v(\mathrm{~km} / \mathrm{h})$ & 28 & 31 & 29.5 & 28 & 28 & 29 & 28.6 & 30 & 26 & 29 \\
\hline $\begin{array}{l}\text { Absolute } \\
\text { difference }\end{array}$ & 1 & 3 & 1.5 & 1.5 & 0 & 1 & 0.4 & 1.4 & 4 & 3 \\
\hline$k(v e h / k m)$ & 69 & 69 & 70 & 71 & 71 & 72 & 72 & 75 & 75 & 78 \\
\hline$v(\mathrm{~km} / \mathrm{h})$ & 25 & 24 & 29 & 30 & 30.6 & 30 & 27 & 28 & 29 & 26 \\
\hline $\begin{array}{l}\text { Absolute } \\
\text { difference }\end{array}$ & 4 & 1 & 5 & 1 & 0.6 & 0.6 & 3 & 1 & 1 & 3 \\
\hline$k(v e h / k m)$ & 80 & 80 & 80 & 83 & 84 & 84 & 85 & 85 & 86 & 87 \\
\hline$v(\mathrm{~km} / \mathrm{h})$ & 30 & 29 & 28 & 25 & 27 & 24 & 23 & 24 & 22 & 16 \\
\hline $\begin{array}{l}\text { Absolute } \\
\text { difference }\end{array}$ & 4 & 1 & 1 & 3 & 2 & 3 & 1 & 1 & 2 & 6 \\
\hline$k(v e h / k m)$ & 88 & 87 & 88 & 89 & 90 & 91 & 92 & 92 & 93 & 94 \\
\hline$v(\mathrm{~km} / \mathrm{h})$ & 17 & 14 & 17 & 15 & 14.5 & 14 & 13 & 11 & 13.5 & 15 \\
\hline $\begin{array}{l}\text { Absolute } \\
\text { difference }\end{array}$ & 1 & 3 & 3 & 2 & 0.5 & 0.5 & 1 & 2 & 2.5 & 1.5 \\
\hline$k(v e h / k m)$ & 96 & 97 & 98 & 98 & 99 & 100 & 103 & 103 & 104 & 105 \\
\hline$v(\mathrm{~km} / \mathrm{h})$ & 14 & 15 & 12 & 11 & 11.5 & 12 & 13 & 12 & 12 & 12.5 \\
\hline $\begin{array}{l}\text { Absolute } \\
\text { difference }\end{array}$ & 1 & 1 & 3 & 1 & 0.5 & 0.5 & 1 & 1 & 0 & 0.5 \\
\hline$k(v e h / k m)$ & 106 & 107 & 108 & 110 & 110 & 112 & 113 & 117 & 118 & 118 \\
\hline$v(\mathrm{~km} / \mathrm{h})$ & 12 & 11.9 & 12 & 11.8 & 12 & 11.4 & 11.5 & 11 & 13 & 11.7 \\
\hline $\begin{array}{l}\text { Absolute } \\
\text { difference }\end{array}$ & 0.5 & 0.1 & 0.1 & 0.2 & 0.2 & 0.6 & 0.1 & 0.5 & 2 & 1.4 \\
\hline$k(\mathrm{veh} / \mathrm{km})$ & 119 & 119 & 119 & 120 & 122 & 122 & 120 & 127 & 128 & 129 \\
\hline$v(\mathrm{~km} / \mathrm{h})$ & 12 & 11.5 & 11.3 & 11.4 & 11.2 & 11 & 10.9 & 10.8 & 11 & 10.7 \\
\hline $\begin{array}{l}\text { Absolute } \\
\text { difference }\end{array}$ & 0.3 & 0.5 & 0.2 & 0.1 & 0.2 & 0.2 & 0.1 & 0.1 & 0.2 & 0.3 \\
\hline$k(v e h / k m)$ & 130 & 130 & 134 & 134 & 136 & 140 & 140 & 141 & 142 & 147 \\
\hline$v(\mathrm{~km} / \mathrm{h})$ & 10.9 & 10.6 & 10.9 & 10.2 & 10.4 & 11 & 10.3 & 10 & 10.2 & 10 \\
\hline $\begin{array}{l}\text { Absolute } \\
\text { difference }\end{array}$ & 0.2 & 0.3 & 0.3 & 0.7 & 0.2 & 0.6 & 0.7 & 0.3 & 0.2 & 0.2 \\
\hline$k(\mathrm{veh} / \mathrm{km})$ & 150 & 150 & & & & & & & & \\
\hline$v(\mathrm{~km} / \mathrm{h})$ & 10.5 & 10 & & & & & & & & \\
\hline $\begin{array}{l}\text { Absolute } \\
\text { difference }\end{array}$ & 0.5 & 0.5 & & & & & & & & \\
\hline
\end{tabular}

Table 2 - Ninety-two speed-density points 
Table 3 - Two groups of points meet Condition 1

\begin{tabular}{||l|c|c|c|c|c|c|c|c||}
\hline$k($ veh/km) & 67 & 67 & 69 & 69 & 70 & 71 & 71 & 72 \\
\hline$v(\mathrm{~km} / \mathrm{h})$ & 26 & 28 & 25 & 24 & 29 & 30 & 30.6 & 27 \\
\hline $\begin{array}{l}\text { Absolute } \\
\text { difference }\end{array}$ & - & 2 & 3 & 1 & 5 & 1 & 0.6 & 3.6 \\
\hline \hline$k($ veh/km) & 84 & 85 & 85 & 86 & 87 & 88 & 87 & 88 \\
\hline$v(\mathrm{~km} / \mathrm{h})$ & 27 & 23 & 24 & 22 & 16 & 17 & 14 & 17 \\
\hline $\begin{array}{l}\text { Absolute } \\
\text { difference }\end{array}$ & - & 4 & 1 & 2 & 6 & 1 & 3 & 3 \\
\hline
\end{tabular}

By analysing Table 3, group one has points which are larger than points before points in highlight, only group two meets Condition 2, so the density value for a key point is 87 .

Compare the goodness of fit of the method of using the Logistic model and the improved method. The square sum of error as a standard is used to evaluate the goodness of fit, as expressed by Equation 3, i.e., the smaller the square sum of error

$$
S S E=\sum\left(x_{i}-x\right)^{2}
$$

the higher is the goodness of fit (denote $x_{i}$ as the fit value, and $x$ is the real value). Use the Logistic model to fit the curve when $k \in[50,87)$. When $k \in[50,87)$ , the SSE of the Logistic model is 105.1502. The fit curve is shown in Figure 10.

Use other models to fit the curve when $k \in[87,150]$. The traffic flow speed-density scatterplot shows that the scatter distribution trend is relatively flat and there is no obvious turning point. Therefore, the curve can be fitted by a linear model and the Underwood model. The result of the linear fitting is shown in Figure 11, which follows the relationship $V=-0.07086 k+20.23$, and $S S E=49.4717$. The result of the Underwood model is shown in Figure 11, which follows the relationship $V=24.09 \exp (-k / 161.1344)$, and $S S E=46.4767$. Therefore, the Underwood model outperforms the linear model when $k \in[87,150]$.

Scale parameters $\theta_{1}$ and $\theta_{2}$ of the Logistic model can be calculated by non-linear least squares method. The arithmetic can be operated by MATLAB. The result of the Logistic model is shown in Figure 12, where $\mathrm{SSE}=183.1346$. The result of comparing the fit method of the Logistic model and the improved fit method is shown in Table 4. As a result, the SSE value of the improved fit method is lower than that of the Logistic model, so the goodness of the improved fit method is better than the Logistic model. Figure 13 shows the fit curve of improved method, and Figure 14 shows both improved curve and Logistic curve. The expression of the improved fit method can be expressed by Equation 4.

$V(k)=$

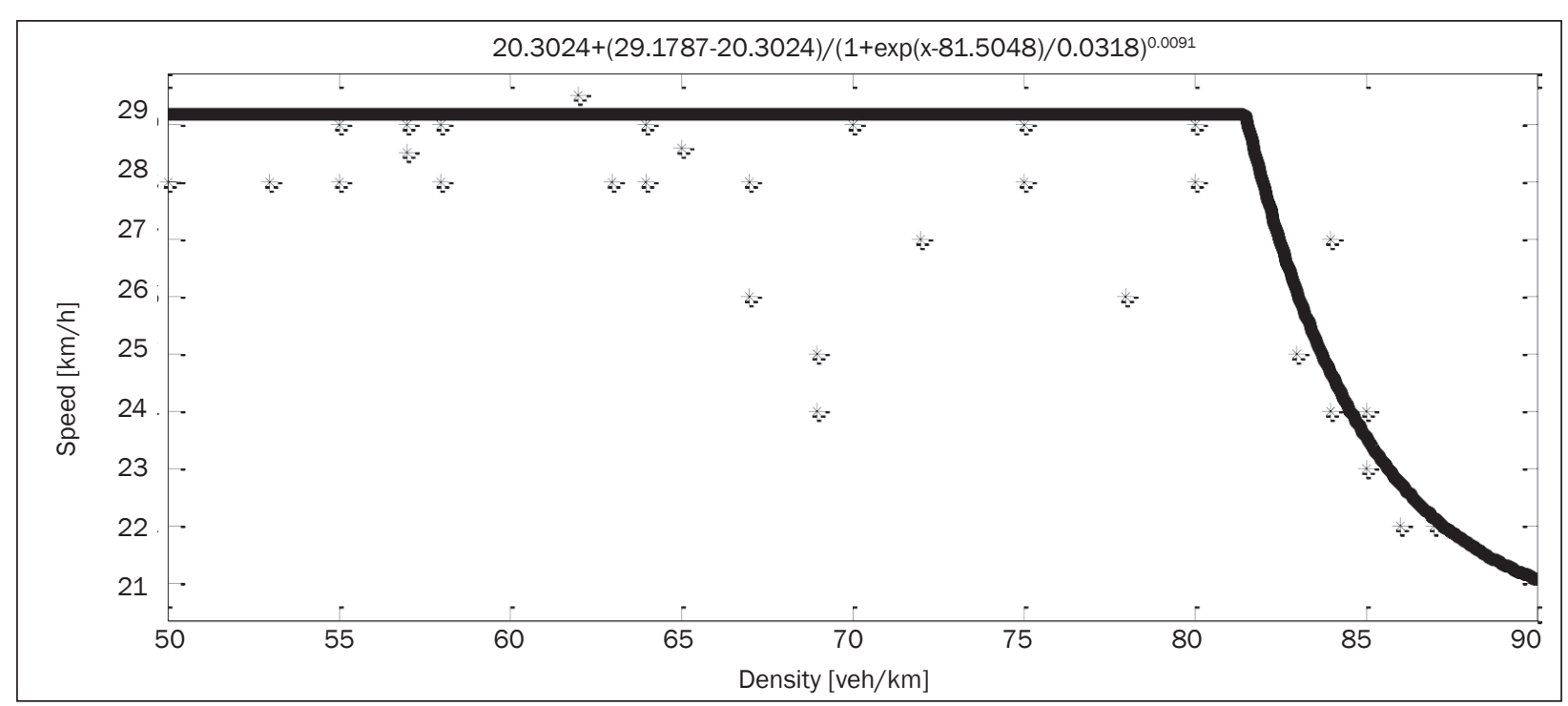

Figure 10 - The fit curve when $k \in[50,87)$ 


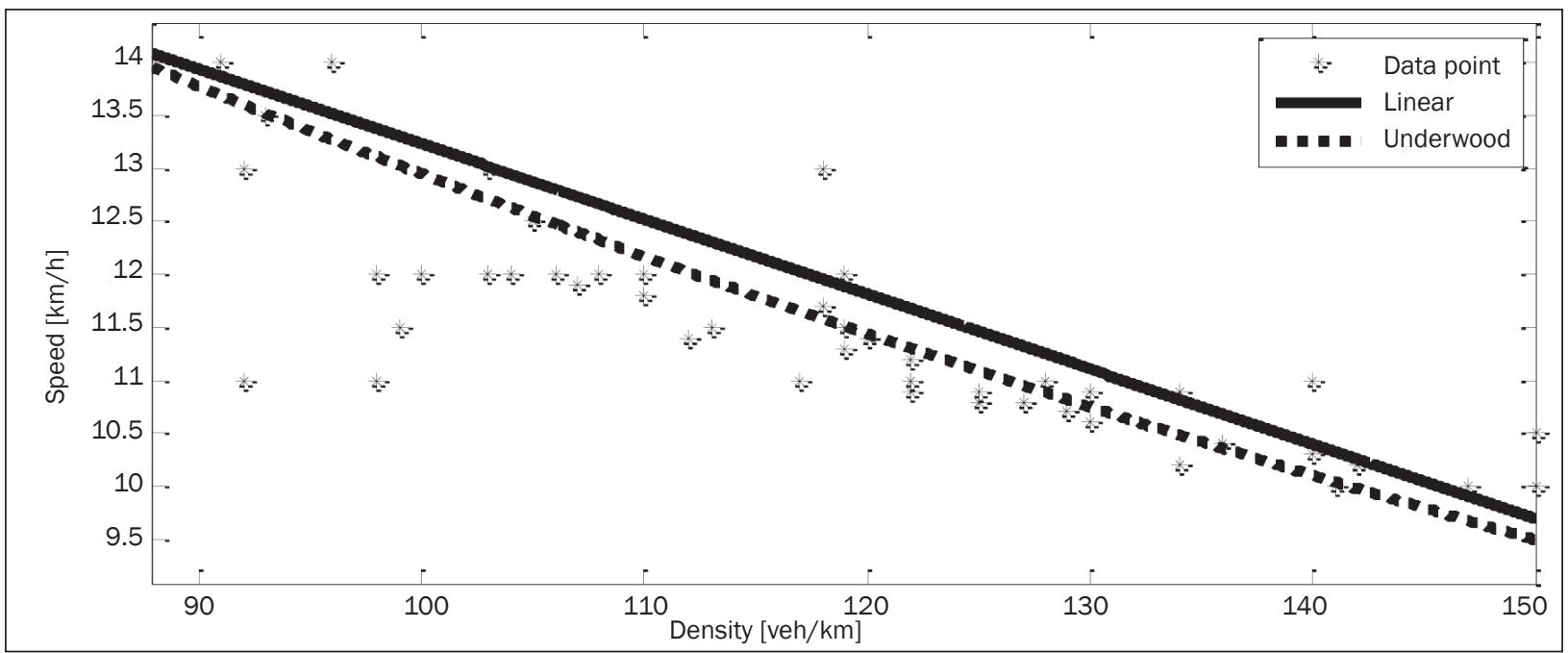

Figure 11 - The fit curve when $k \in[87,150]$

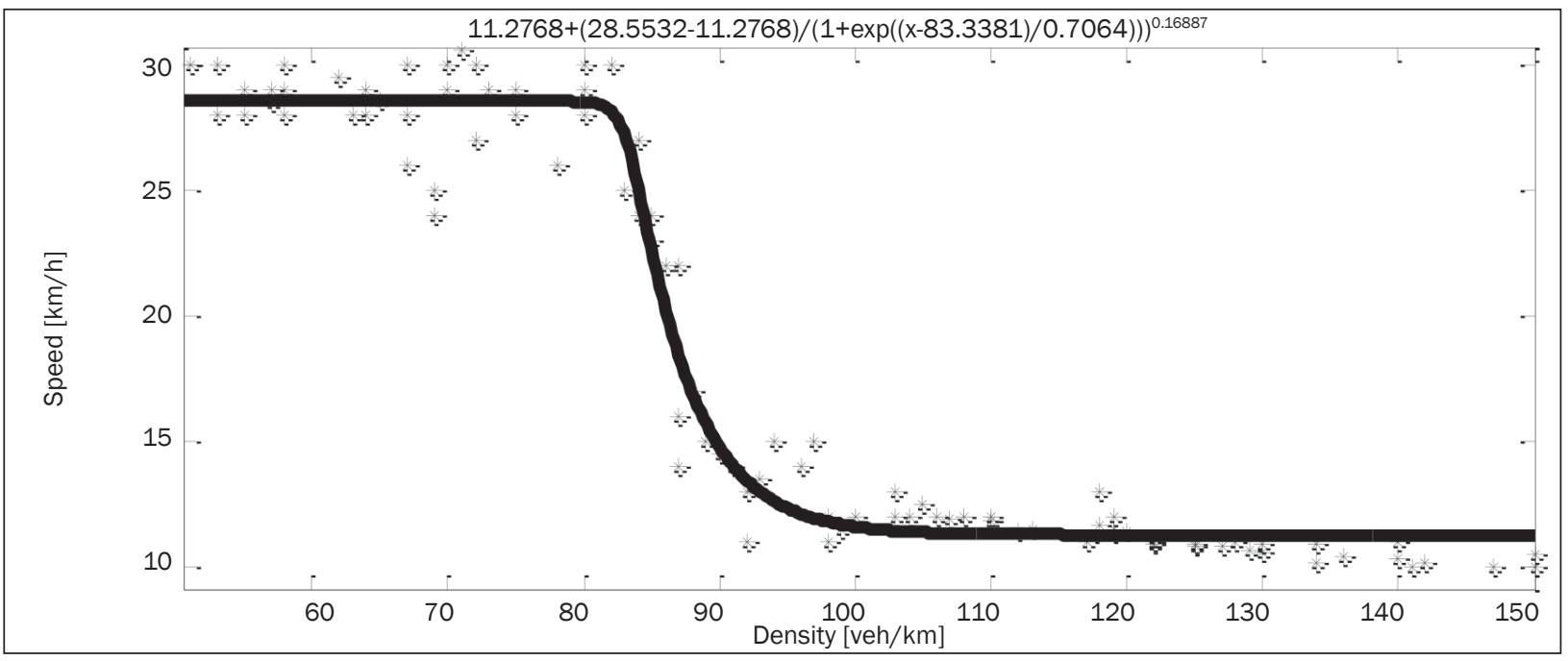

Figure 12 - The fit curve of the Logistic model

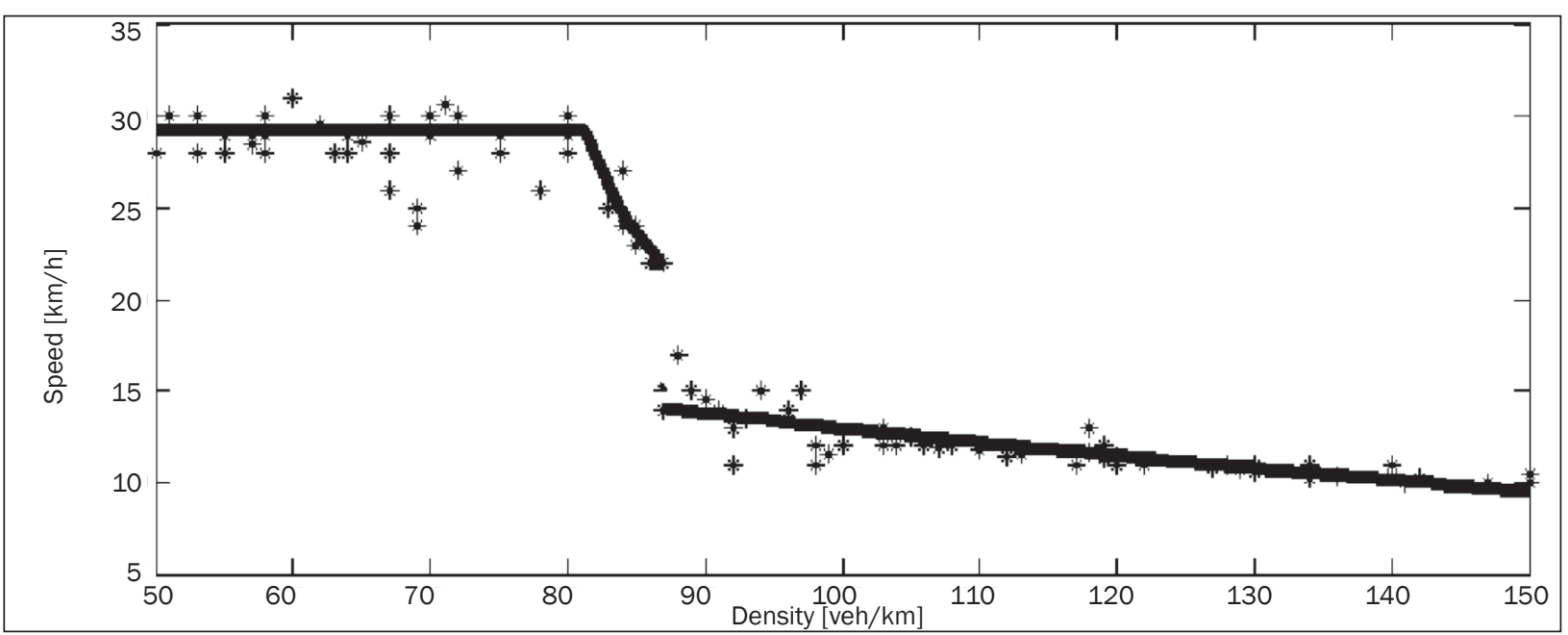

Figure 13 - The fit curve of improved method 


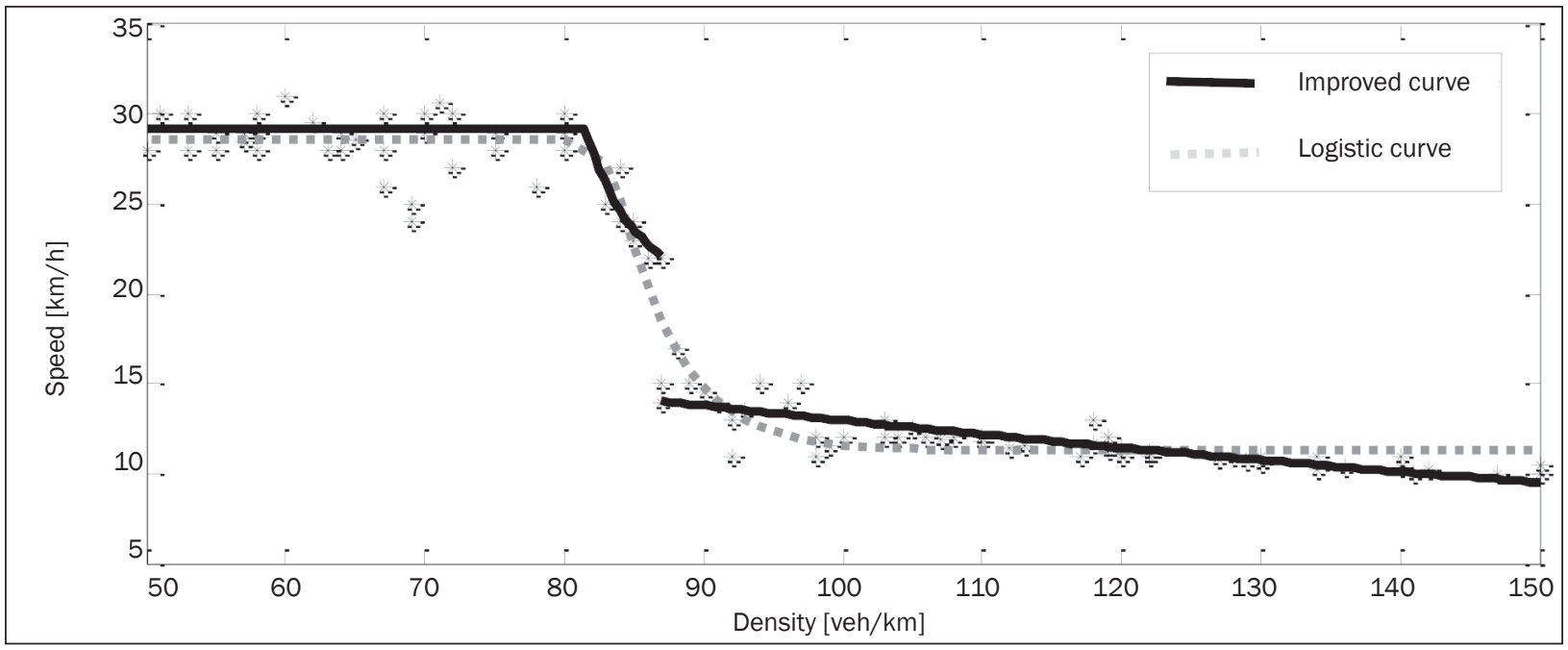

Figure 14 - Both improved curve and Logistic curve

Table 4 - The result of comparing the fit method of the Logistic model and the improved fit method

\begin{tabular}{||l|l|c||}
\hline \multicolumn{1}{|c|}{ Method } & \multicolumn{1}{|c||}{ Expression } & SSE \\
\hline \hline Logistic Model & a. 11.2768+17.2764/(1+exp $((x-83.3381) / 0.7064)))^{\wedge} 0.1687$ & 183.1346 \\
\hline \multirow{2}{*}{ Improved method } & a. 20.3024+8.8763/(1+exp $((x-81.5048) . / 0.0318)) .^{\wedge} 0.0091$ & \multirow{2}{*}{151.6219} \\
\cline { 2 - 3 } & b. 24.09exp(-x/161.1344) & \\
\hline
\end{tabular}

\section{A METHOD TO INSERT VIRTUAL DATA POINTS INTO THE INITIAL DATA}

\subsection{Method}

The above analysis shows that when traffic flow density increases to a certain point, traffic flow speed jumps down suddenly. However, the mathematical characteristics of the speed-density relationship should be studied further, so it needs a uniform function (not piecewise function) which has good mathematical properties. Therefore, inserting virtual data points into the initial data makes the fitting curve be continuous so that the Logistic model can be used to fit the curve well [13]. According to the function of the Logistic model, some key characteristics can be obtained. There is a group of data points, $\left(x_{i}, y_{i}\right)$, where $x_{1}$ $\leq x_{2} \leq x_{3} \leq \ldots \leq x_{n-2} \leq x_{n-3} \leq x_{n}$, and let $x_{T}$ be the density value of the key point.

In order to make the problem simple and general the virtual data points are defined to have specific characteristics. For any $x_{i}$, there is the same number of $y_{i}$. The relationship between $x_{i}$ and the average value of $y_{i}$ is linear, and set $\left\{x_{i}\right\}$ is an arithmetic sequence. The process of inserting virtual data points can be divided into two steps:

Step 1: Build the upper and the lower boundary model of the speed-density scatterplot. Denote $f(x)$ as the linear expression of the lower boundary of the speed-density scatterplot when $x \in\left[x_{1}, x_{T}\right)$; denote $g(x)$ as the linear expression of the upper boundary of the speed-density scatterplot when $x \in\left[x_{T}, x_{n}\right]$. Scat- terplot values of the upper and the lower boundary can be used to determine functions $g(x)$ and $f(x)$ by linear fitting. The ideal boundary scatterplots should satisfy:

$$
\forall\left(x_{i}, y_{i}\right)\left(x_{j}, y_{j}\right) \in A, x_{i} \leq x_{j} \rightarrow y_{i}>y_{j}
$$

where $A$ is upper boundary set of points, $B$ is lower boundary set of points and B's condition is the same as $A$ 's.

Step 2: Construct and insert virtual data points into the initial data. Virtual data points set is denoted by Set $S$. Assume that there is a group of virtual data points ( $x$, $\left.y_{i}\right)$, as an $x$-value has many $y$-values. Therefore, there exists $\left(x, y_{0}\right)$ minimising $\sum_{i=1}^{n}\left(y_{0}-y_{i}\right)^{2}$. Assume:

$H\left(y_{0}\right)=\sum_{i=1}^{n}\left(y_{0}-y_{i}\right)^{2}$

the derivative of Equation 6 is:

$$
H^{\prime}\left(y_{0}\right)=2 n y_{0}-2 \sum_{i=1}^{n} y_{i}
$$

Let $H^{\prime}\left(y_{0}\right)=0$, so $y_{0}=\sum_{i=1}^{n} y_{i} / n$, which minimize $H\left(y_{0}\right)$. For the fitting result, the value of the point is the average of $y_{i}$. Therefore, virtual data points should meet:

$$
\begin{aligned}
& g\left(x_{i}\right) \leq y_{i} \leq f\left(x_{i}\right), \forall\left(x_{i}, y_{i}\right) \in S \\
& \sum_{k=1}^{n} y_{1}^{k} / n>\sum_{k=1}^{n} y_{2}^{k} / n>\ldots>\sum_{k=1}^{n} y_{m}^{k} / n, \\
& \forall\left(x_{i}, y_{i}^{k}\right) \in S, x_{1}<x_{2}<\ldots<x_{m}
\end{aligned}
$$

where, $i=1,2, \ldots m, k=1,2, \ldots, n$ and $\varepsilon$ should meet:

$\exists \varepsilon, T-\varepsilon \leq x_{i} \leq T+\varepsilon, \forall\left(x_{i}, y_{i}\right) \in S$ 
At the same time, assume that there is a line which passes through $\left(x_{T} \varepsilon, f\left(x_{T}-\varepsilon\right)\right),\left(x_{T}+\varepsilon, g\left(x_{T}+\varepsilon\right)\right)$, and $\left[x_{i}, \sum_{i-1}^{n} y_{i}^{k} / n\right]$, so virtual data points can be found by above conditions.

\subsection{Computational experiments}

Scatterplot values of the upper and the lower boundary are given in Table 5 . The ideal boundary scatterplot is given in Table 6.

Scatterplot values of the upper and the lower boundary can be used to determine functions $g(x)$ and $f(x)$ by linear fits. The results are shown in Figure 15

where $R$-square of $f(x)$ is 0.8189 and $R$-square of $g(x)$ is 0.8527 , and the fit result is ideal.

In Figure 15, the number of points in the length of the black dotted line should be equal to the number of points in the length of the grey dotted line because it is assumed that the linear density of points is approximate. Therefore, when $\varepsilon=5, m=5$, and $n=3$, the virtual data points can be found by this method, and the values of 15 virtual data points are given in Table 7.

\subsection{Mathematical characteristics of the speed- density relationship}

Table 5 - Scatterplot values of the upper and the lower boundary

\begin{tabular}{|c|c|c|c|c|c|c|c|c|c|c|c|c|c|c|}
\hline \multirow{4}{*}{$\begin{array}{l}\text { The upper } \\
\text { boundary }\end{array}$} & Density & 53 & 55 & 57 & 58 & 64 & 67 & 69 & 72 & 75 & 80 & 84 & 85 & 87 \\
\hline & Speed & 30 & 29 & 29 & 30 & 29 & 30 & 25 & 30 & 29 & 30 & 27 & 24 & 22 \\
\hline & Density & 92 & 98 & 103 & 110 & 118 & 119 & 122 & 125 & 130 & 134 & 140 & 147 & 150 \\
\hline & Speed & 13 & 12 & 13 & 12 & 13 & 12 & 11.2 & 10.9 & 10.9 & 10.9 & 11 & 10.6 & 10.5 \\
\hline \multirow{4}{*}{$\begin{array}{l}\text { The lower } \\
\text { boundary }\end{array}$} & Density & 53 & 55 & 57 & 58 & 64 & 67 & 69 & 72 & 75 & 30 & 84 & 85 & 87 \\
\hline & Speed & 28 & 28 & 28.5 & 28 & 28 & 26 & 24 & 27 & 28 & 28 & 24 & 23 & 14 \\
\hline & Density & 92 & 98 & 103 & 110 & 118 & 119 & 122 & 125 & 130 & 134 & 140 & 147 & 150 \\
\hline & Speed & 11 & 11 & 12 & 11.8 & 11.7 & 11.3 & 10.9 & 10.8 & 10.6 & 10.2 & 10.3 & 10 & 10.1 \\
\hline
\end{tabular}

Table 6 - Filtrated scatterplot values of the upper and the lower boundary

\begin{tabular}{|c|c|c|c|c|c|c|c|c|c|c|c|c|c|c|}
\hline \multirow{4}{*}{$\begin{array}{l}\text { The upper } \\
\text { boundary }\end{array}$} & Density & 53 & 55 & 57 & - & 64 & - & 69 & - & - & - & - & 85 & 87 \\
\hline & Speed & 30 & 29 & 29 & - & 29 & - & 25 & - & - & - & - & 24 & 22 \\
\hline & Density & 92 & 98 & - & 110 & - & 119 & 122 & 125 & 130 & 134 & - & 147 & 150 \\
\hline & Speed & 13 & 12 & - & 12 & - & 12 & 11.2 & 10.9 & 10.9 & 10.9 & - & 10.6 & 10.5 \\
\hline \multirow{4}{*}{$\begin{array}{l}\text { The lower } \\
\text { boundary }\end{array}$} & Density & 53 & 55 & - & 58 & 64 & 67 & 69 & - & - & - & 84 & 85 & 87 \\
\hline & Speed & 28 & 28 & - & 28 & 28 & 26 & 24 & - & - & - & 24 & 23 & 14 \\
\hline & Density & 92 & 98 & - & - & - & - & 122 & 125 & 130 & 134 & - & 147 & - \\
\hline & Speed & 11 & 11 & - & - & - & - & 10.9 & 10.8 & 10.6 & 10.2 & - & 10 & - \\
\hline
\end{tabular}

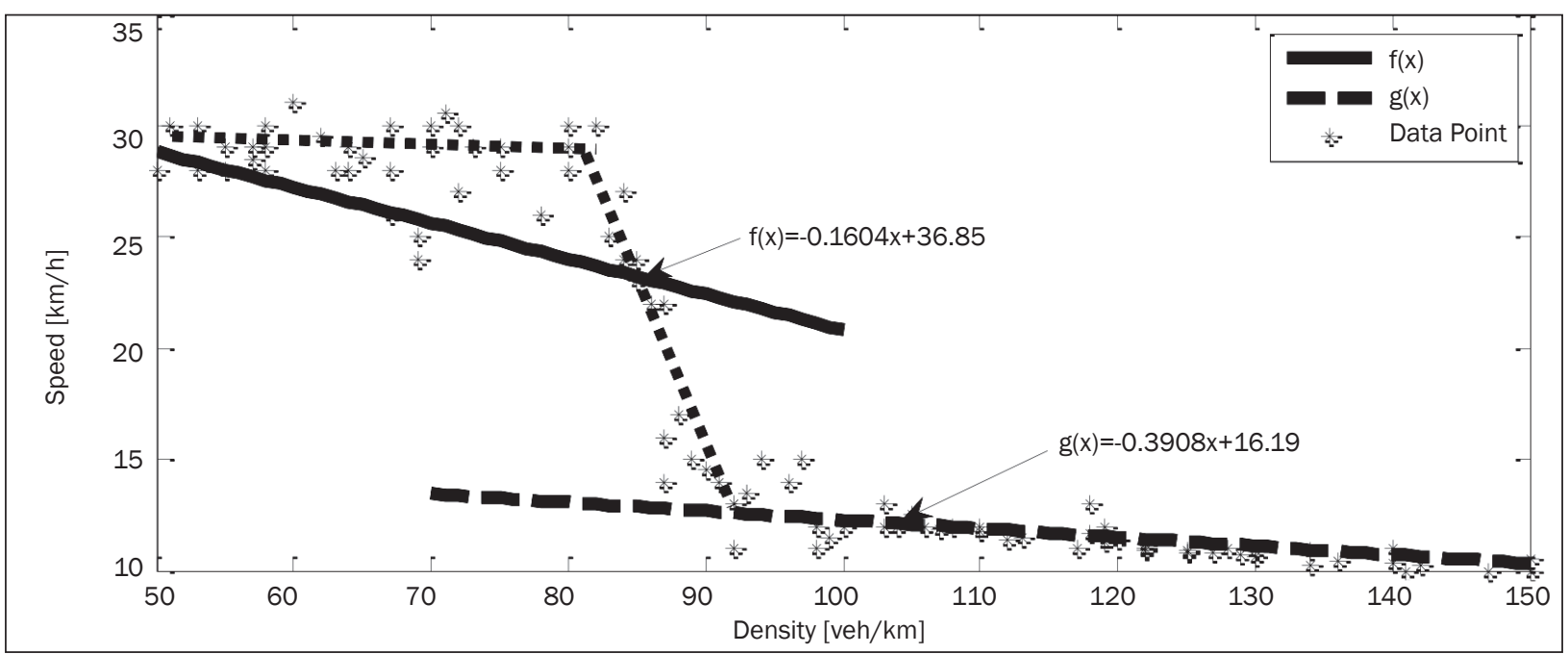

Figure 15 - The fit result of the upper and the lower boundary model 
Table 7 - Values of 15 virtual data points

\begin{tabular}{||c|c|c|c|c|c||}
\hline \multirow{2}{*}{ Interval } & \multicolumn{5}{|c|}{ Virtual data points } \\
\hline \hline \multirow{2}{*}[82,92]{} & $(83,22.59)$ & $(85,21.37)$ & $(87,18.15)$ & $(89,15.93)$ & $(91,13.70)$ \\
\cline { 2 - 6 } & $(83,23.49)$ & $(85,20.37)$ & $(87,20.15)$ & $(89,16.93)$ & $(91,14.70)$ \\
\cline { 2 - 6 } & $(83,21.69)$ & $(85,19.37)$ & $(87,16.15)$ & $(89,14.93)$ & $(91,12.70)$ \\
\hline
\end{tabular}

The Logistic model is used to fit points which are the inserted 15 virtual data points, and the fit curve is shown in Figure 16 where $v_{f}=10.6720, v_{b}=29.1181$, $k_{t}=81.1199, \theta_{1}=0.0694, \theta_{2}=0.0105$. From Equation 1 , let $\alpha=\exp \left(\frac{k^{-}-k_{t}}{\theta_{1}}\right)$, when $\alpha \rightarrow \infty, V \rightarrow v_{b}$, see the fit result, $v_{b}=10.6720$. When $k=50, \alpha \approx 0$, so, the speed can be as the lowest average speed around flyover work zones. When $\alpha \rightarrow 0, V \rightarrow v_{f}$, see the fit result, $v_{f}=10.6720+18.4461=29.1181$, when $k=150, \alpha \rightarrow \infty$, so the speed can be regarded as the highest average speed around flyover work zones. As can be seen from Figure 16 , when $k \geq 87 \mathrm{veh} / \mathrm{km}$, the downtrend of speed is smooth and slow, when the density increases from $90 \mathrm{veh} / \mathrm{km}$ to $150 \mathrm{veh} / \mathrm{km}$, the speed reduces from $15 \mathrm{~km} / \mathrm{h}$ to $10 \mathrm{~km} / \mathrm{h}$. However, when $\mathrm{k}<87 \mathrm{veh} / \mathrm{km}$, the situation is different. From Figure 14, an important point can be found, which is $k=80 \mathrm{veh} / \mathrm{km}$. When $k$ $\leq 80 \mathrm{veh} / \mathrm{km}$, it can be found that the speed uniformly increases from $28 \mathrm{~km} / \mathrm{h}$ to $30 \mathrm{~km} / \mathrm{h}$. When 80 veh/ $\mathrm{km}<k<87 \mathrm{veh} / \mathrm{km}$, the downtrend of speed is so fast that the discontinuity point arises when $k=87$ veh/ $\mathrm{km}$. Therefore, when $80 \leq k \leq 87$, the traffic flow is in the unstable state, which may cause traffic accidents during the state around the flyover work zones.
The traffic volume at the flyover work zones can be divided into two parts: one part belongs to vehicles going straight on the arterial road, the other part belongs to vehicles merging into the arterial road. The change of traffic volume of the work zone is small for a long time, but it is not stable for a short time. It is noted that the traffic volume of Section $C$ is much larger than the traffic volume of Section B. And the spot speed at the work zone is very low. The fitting result of the improved method is better than the fit result of the Logistic model. The method to insert virtual data points into the initial data is simple and effective, which makes initial scatterplot become continuous and smooth so that it can be used to analyse the mathematical characteristics of the speed-density relationship. This paper proposes a method to solve the fit problem which has a discontinuity point, and it gives a method to insert virtual data points into the initial data in order to study the mathematical characteristics. In order to find general methods to analyse the traffic flow, the next work includes the study of other kinds of work zones and the exploration of the relationship between the discontinuity point and the actual traffic conditions.

\section{CONCLUSION}

\section{ACKNOWLEDGEMENT}

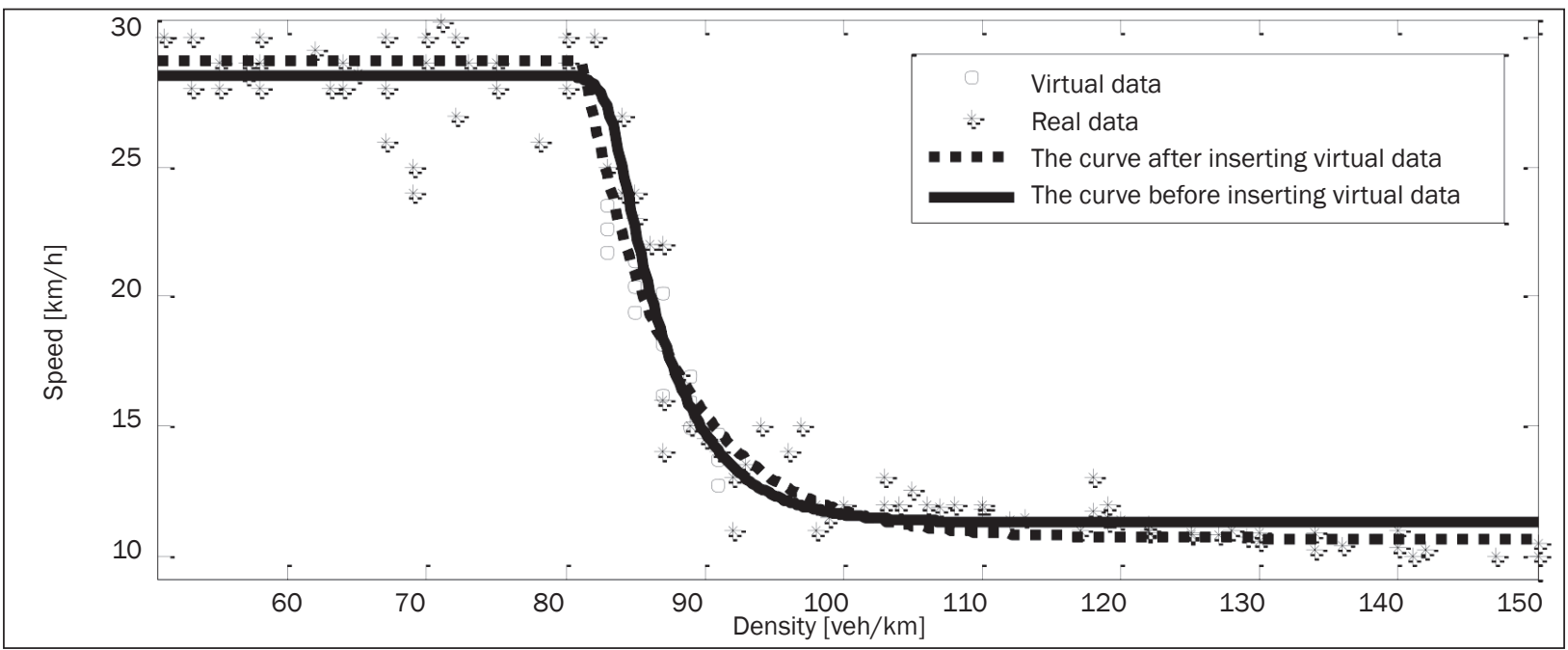

Figure 16. - The Logistic model curve after inserting virtual data and the curve before inserting virtual data 
This work was partly supported by the National Natural Science Foundation of China (Grant No. 712620), Natural Science Foundation of Inner Mongolia Autonomous Region (Grant No. 2016MS0501), Scientific Research Foundation for the Returned Overseas Chinese Scholars, State Education Ministry, and Young Talent on Science and Technology Program of the University in Inner Mongolia (Grant No. NJYT-13-B02).

曹瑾金鎂（通讯作者），刘小寒 摘要

高架路施工区周边均衡速度-密度关系研究

目前, 日益增长的城市交通需求已达到现有交通 基础设施的通行能力。为了减轻交通压力, 提升路 网通行能力, 建设高架路成为大多数城市提升路网 效率的首选。高架路建设期间, 施工区占据原有道 路空间, 影响交通流特性、驾驶行为, 从而极大地 降低了道路通行能力。研究高架路建设期间的交通 流特性, 将有助于施工区周边交通组织和交通安全 的改善。本研究基于中国呼和浩特市高架路建设施 工区的实测数据，对周边交通流特性进行分析。研 究发现传统Logistic模型并不适用于描述高架路施工 区周边交通流均衡速度-密度关系。在深入研究和分 析交通流特性和驾驶行为的基础上, 本文提出了改 进Logistic模型用以描述高架路施工区周边交通流均 衡速度-密度关系。为了分析速度一密度关系的数学 特性, 本文还提出了一种插入虚拟数据点的方法, 提高拟合优度。

\section{关键词}

高架路; 交通流特性; Logistic 模型; 施工区

\section{REFERENCES}

[1] Enberg A, Mannan MS. Capacity and Traffic Characteristics at a Freeway Work Zone in Finland. Proceedings of the 3rd International Symposium on Highway Capacity; 1998 June 22-26; Copenhagen, Denmark; 1998. p. 397-421.

[2] Sisiopiku VP, Lyles RW, Krunz M, Yang Q, Akin D, Abbasi M. Study of Speed Patterns in Work Zones. Proceedings of the 78th Transportation Research Board Annual Meeting, Washington, D.C.; 1999.

[3] Jiang Y. Traffic Capacity, Speed and Queue-Discharge Rate of Indiana's Four-Lane Freeway Work Zone. In- diana Department of Transportation Division of Research; 1999.

[4] Zhou M, Wu B, Gai S. Micro-simulation of Factors Affecting Passing Capacity in Freeway Maintenance Work Zones [in Chinese]. Computer and Communications. 2004;22(6):54-57.

[5] Radhakrishnan RV, Sun C, et al. Traffic Flow Characteristics of a Congested Work Zone in Missouri. Proceedings of the 2007 Mid-Continent Transportation Research Symposium; 2007 August 16-17; Ames, lowa; 2007.

[6] Chen Y, Shao C. Simulation for Work Zone Traffic Capacity [in Chinese]. Communications Standardization. 2010;23:190-194.

[7] Meng Q, Weng J. An improved cellular automata model for heterogeneous work zone traffic. Transportation Research Part C: Emerging Technologies. 2011;19(6):1263-1275.

[8] Weng J, Meng Q. Effects of environment, vehicle and driver characteristics on risky driving behaviour at work zones. Safety Science. 2011;50(4):1034-1042.

[9] Hong Y, Ozbay K, Ozturk O, Yildirimoglu M. Modeling work zone crash frequency by quantifying measurement errors in work zone length. Accident Analysis \& Prevention. 2013;55:192-201.

[10] Weng J, Meng Q, Yan X. Analysis of work zone rear-end crash risk for different vehicle-following patterns. Accident Analysis and Prevention. 2014;72:449-457.

[11] Xie G, Liu D, Xu X. Traffic organization and design around urban flyover work zones [in Chinese]. Urban Roads Bridges \& Flood Control. 2014;46-56.

[12] Weng J, Xue S, Yang Y, Yan X, Qu X. In-depth analysis of drivers' merging behaviour and rear-end crash risks in work zone merging areas. Accident Analysis \& Prevention. 2015;77:51-61.

[13] Wang H, Li Y, Chen Q-Y, Ni D. Logistic modeling of the equilibrium speed-density relationship. Transportation Research Part A: Policy and Practice. 2011;45(6):554-566.

[14] Underwood RT. Speed, Volume, and Density Relationship: Quality and Theory of Traffic Flow. New Haven, Connecticut: Yale Bureau of Highway Traffic; 1961. p. 141-188. 